\title{
Effect of Placement of Inoculum of Gaeumannomyces graminis var. tritici on Severity of Take-all in Winter Wheat
}

\author{
Mehdi Kabbage and William W. Bockus, Department of Plant Pathology, Kansas State University, Manhattan \\ 66506
}

\begin{abstract}
Kabbage, M., and Bockus, W. W. 2002. Effect of placement of inoculum of Gaeumannomyces graminis var. tritici on severity of take-all in winter wheat. Plant Dis. 86:298-303.

Take-all, caused by Gaeumannomyces graminis var. tritici, is one of the most important root diseases of wheat worldwide. Because of the lack of highly effective chemical control, cultural practices, such as crop rotation, play a major role in managing disease severity. In Kansas, many producers do not use these measures and continue to suffer losses from take-all. Greenhouse and field experiments were established to assess the effect of horizontal versus vertical distribution of G. graminis var. tritici inoculum on disease severity. Oat kernel inoculum was placed at 0 (seed level), 5,10 , or $15 \mathrm{~cm}$ below the wheat seed or 5,10 , or $15 \mathrm{~cm}$ to the side of the wheat seed at a depth of $5 \mathrm{~cm}$. Inoculum spatial location and distance greatly influenced take-all. Experiments showed more severe losses due to take-all when inoculum was placed below the seed than to the side of the seed. Regression analyses were used to develop take-all risk models relating inoculum distance from the seed to yield loss. Quadratic models were a better fit for data from experiments where inoculum was placed to the side of the seed, whereas linear models significantly fit data from experiments where inoculum was positioned below the seed. Within the same direction, take-all decreased as the inoculum was placed at greater distances from the seed, often to insignificant levels at 10 to $15 \mathrm{~cm}$. According to the regression models, significant reduction ( $\geq 50 \%$ ) in take-all might be achieved by plowing under the infested residues (crowns) to depths greater than $15 \mathrm{~cm}$, or placing seed $>6.0 \mathrm{~cm}$ to the side of inoculum. Therefore, under no-till conditions, sowing parallel to and exactly between the previous years' stubble rows (inoculum) might help manage take-all. These possibilities need to be investigated under field conditions.
\end{abstract}

The take-all fungus, Gaeumannomyces graminis (Sacc.) Arx \& D. Olivier var. tritici J. Walker, infects the roots and crowns of winter wheat (Triticum aestivum L.) cultivars, resulting in reduced water and nutrient uptake. The black color of the basal stem is a characteristic symptom of the disease. The fungus kills tillers of infected plants; therefore, kernels are severely shriveled. As its name implies, complete crop failures can occur when the disease is severe.

In Kansas, take-all is most severe in the eastern and central part of the state, where precipitation allows for annual cropping of wheat. However, it also develops in the irrigated areas in the west. The fungus parasitizes the host plant, or occurs in host residues in the soil in a saprophytic stage (14). It also is sensitive to thermal inactiva-

Corresponding author: W. W. Bockus

E-mail: bockus@plantpath.ksu.edu

Kansas Agricultural Experiment Station Contribution No. 01-439-J. This project was supported in part by a grant from the Kansas Wheat Commission.

Accepted for publication 21 November 2001.

Publication no. D-2002-0114-05R

(C) 2002 The American Phytopathological Society tion when moist soils are heated by the sun (3). The fungus is a poor saprophyte and does not compete well with the natural soil microflora $(4,8,11,13)$. The inoculum in soil from a previous host crop (wheat) initiates the primary infection by close proximity to or contact between infested residues and susceptible roots (1). When host plants are not present, inoculum in the soil undergoes a declining phase as soil microbes decompose residues. As a result, the take-all fungus rapidly loses its disease-causing potential during a fallow period (10).

No highly effective chemical control is commercially available; therefore, crop management practices represent an important approach in limiting take-all expression (6). Crop rotation to nonhost species has a major influence on take-all by taking advantage of the poor competitive saprophytic ability of the fungus $(5,7)$. However, farmers do not follow this recommendation in many areas of Kansas where wheat monoculture is popular due to the lack of appropriate alternative winter crops (2). Models developed by Bailey and Gilligan (1) showed that the proportion of primary inoculum capable of causing infection decreases exponentially over time. Therefore, delayed planting can limit take-all by forcing the fungus to extend its saprophytic phase. Nevertheless, this practice favors soil erosion and may reduce yields (2).
Reports from Europe and western Australia showed that conventional tillage had no effect or increased take-all compared with direct drilling $(6,9)$. In the United States, however, direct drilling of wheat seed into soils where take-all occurs naturally resulted in more take-all compared with conventional tillage methods, such as moldboard or disk plowing. This is mainly due to the fact that with tillage practices, residues harboring $G$. graminis var. tritici are broken into small pieces, speeding up the process of degradation by soil microbes $(15,18)$. Additionally, burying the residues eliminates their shading effect, thus exposing the fungus to inactivation by high summer temperatures (3). Although reduced take-all is expected when conventional tillage (moldboard plow) is performed as soon as possible after harvest (16), erosion problems associated with conventional tillage practices are a big concern in many regions. Clearly, there is a need for additional and improved crop management practices to help limit losses from take-all in Kansas.

The experiments reported in this paper were conducted to develop predictive regression models relating inoculum distance from the seed to the amount of yield loss due to the disease. The effect of horizontal versus vertical distribution of inoculum of G. graminis var. tritici on severity of takeall also was investigated.

\section{MATERIALS AND METHODS}

Inoculum growth and preparation. Oat kernels colonized by $G$. graminis var. tritici were used as a source of inoculum in both greenhouse and field experiments. $G$. graminis var. tritici isolate RP-2 (from a commercial wheat field in Republic County, KS), which was the most virulent among those tested prior to the experiment, was grown at $20^{\circ} \mathrm{C}$ on one-fourth-strength potato dextrose agar (PDA) in petri plates for about 1 week.

Oat kernels $(140 \mathrm{~g})$ and $150 \mathrm{ml}$ of distilled water were placed in a 1-liter canning jar that was capped with a perforated, cotton-plugged lid. The jars were shaken and incubated for $16 \mathrm{~h}$ to allow the oats to imbibe most of the water. After this period, jars were reshaken and autoclaved $\left(125^{\circ} \mathrm{C}\right)$ for $60 \mathrm{~min}$. The oat kernels were allowed to cool in a laminar-flow hood before adding four plugs of colonized agar from a fresh culture of G. graminis var. tritici. The jars then were placed on a laboratory bench 
and incubated at room temperature for 3 weeks.

Every 4 to 5 days, the jars were shaken to promote uniform and simultaneous colonization of the oat growth medium and help prevent clumping of kernels. Oat kernels are thoroughly colonized when the fungus mycelium causes a black color on the kernels. After the incubation period, the inoculum was spread on a shallow tray and air dried in the laboratory. Air-dried inoculum will maintain viability and pathogenicity for 3 to 6 months at $25^{\circ} \mathrm{C}$, but will store considerably longer at $4^{\circ} \mathrm{C}$. A pathogenicity test was conducted to determine if the inoculum caused characteristic symptoms of take-all on wheat before it was used as a source of inoculum in both greenhouse and field experiments.

Greenhouse experiments. Experiments were conducted during the fall of 1999 and the winter of 2000 at the Kansas State University greenhouse complex, Manhattan, KS. Five seeds per pot of the winter wheat cv. Karl 92 were sown together in one "hill" (clump), $5 \mathrm{~cm}$ below the soil surface. After emergence, seedlings were thinned to three per pot. Pots were $30 \mathrm{~cm}$ tall by $27.5 \mathrm{~cm}$ (top diameter) by $25 \mathrm{~cm}$ (bottom diameter) (Hummert International, Earth City, MO). Nonsterile soil (Kennebek silty clay loam) was mixed with vermiculite (2:1, soil:vermiculite, vol/vol) and used as a growth medium. Three $G$. graminis var. tritici-colonized oat kernels were introduced in a clump at planting into each pot at different distances from the clump of wheat seed, as described below. Control pots did not receive any inoculum.

Experiments were arranged in a randomized complete block design with nine treatments and 10 replications (pots). Treatment 1 was the noninoculated control. Treatment 2 had inoculum placed at the seed level. In treatments 3,4 , and 5 , the inoculum was positioned at 5,10 , or $15 \mathrm{~cm}$ directly below the seed, respectively. In treatments 6,7 , and 8 , the inoculum was placed at 5,10 , or $15 \mathrm{~cm}$ to the side of the wheat seed, respectively. For treatment 9 , inoculum was positioned $2.5 \mathrm{~cm}$ directly above the seed level.

Pots were watered daily, fertilized shortly after seedling emergence with a soluble fertilizer $(20: 20: 20, \mathrm{~N}: \mathrm{P}: \mathrm{K})$ at the rate of $0.3 \mathrm{~g} / \mathrm{pot}$, and maintained in the greenhouse $\left(19 \pm 4^{\circ} \mathrm{C}\right)$ without supplemental light. Plants were grown for 6 weeks before harvest and the experiment was conducted twice.

Field experiments. Field experiments were conducted during two growing seasons (1992-93 and 1999-2000) at the Kansas State University Plant Pathology Experimental Field near Manhattan, KS. The soil is a Chase silty clay loam $(\mathrm{pH} 6.5$, $2.0 \%$ organic matter). Wheat had not been grown at this location during the year prior to the experiments, rendering the soil free of naturally occurring $G$. graminis var. tritici (3). The plot area was moldboard plowed and then disked and spike-tooth harrowed before planting.

Experiments were arranged in a randomized complete block design with five replications, with the same nine treatments described above for greenhouse experiments. Plots were single rows $6.1 \mathrm{~m}$ long and $91 \mathrm{~cm}$ apart. Whole oat kernels, colonized by $G$. graminis var. tritici, were introduced immediately before sowing by hand digging trenches in the appropriate location parallel to the row of seed. For inoculum placed below the seed, kernels were added to the trench and covered with soil to seed level, after which the seed was sown and covered with soil. Previous experiments at this site showed that $0.43 \mathrm{~g}$ of inoculum per meter of row (regardless of row spacing) produced take-all that resulted Therefore, each row received $2.6 \mathrm{~g}$ of inoculum placed in a parallel row at different distances from the row of seed, depending on the treatment. In each plot, $6 \mathrm{~g}$ of wheat seed $(60 \mathrm{~kg} / \mathrm{ha})$ was planted $5 \mathrm{~cm}$ below the surface. The noninoculated control did not receive any inoculum. Plots were seeded during the third week of September in both years with the winter wheat cv. Karl 92.

Plots were sprinkler irrigated immediately after planting and whenever needed throughout the growing seasons. The soil at the Plant Pathology Experiment Field had sufficient levels of potassium and phosphorus as indicated by soil tests, but nitrogen $\left(\mathrm{NH}_{4} \mathrm{NO}_{3}, 34 \% \mathrm{~N}\right)$ supplements were applied for maximum yield potential. Weeds were controlled by hand hoeing.

Disease and yield assessment. After a growth period of 6 weeks in the greenhouse ( 3 to 4 fully expanded leaves), fresh weights of plant parts above the soil level were measured. Fresh weight yield losses due to take-all were calculated by comparing yields with those from the noninocuin 50 to $80 \%$ yield loss (unpublished data).

lated controls within a replication. For disease evaluation, roots were removed from the pots, washed free of soil and vermiculite, and stored at $4^{\circ} \mathrm{C}$ a maximum of 3 days until being rated. Roots were scored by visual assessment under a dissecting microscope based on the percentage $(1,5$, $10,25,50,75$, or $100 \%$ ) of the root system (seminal and crown roots) showing brownblack root rot or runner hyphae.

In the field, take-all severity was assessed by a visual estimation of the percentages of stunted plants and prematurely ripened wheat heads (whiteheads) at anthesis (growth stage 60). Wheat was harvested with a small-plot combine (harvested area 0.3 by $5.1 \mathrm{~m}$ ) in June. Wheat grain from each row was weighed and grain yields determined. Yield losses from take-all were calculated by comparing yields with those from the noninoculated controls within a replication.

Statistical analyses. The treatment where the inoculum was placed above seed level had only two locations ( 0 and $2.5 \mathrm{~cm}$ above) for comparison; therefore, regression techniques could not be used to compare these data with the side and below treatments. Therefore, analysis of variance was used for comparisons of the $2.5-\mathrm{cm}$ above treatment with the other treatments. Fisher's least significant difference (LSD) or the $F$-protected $t$ test method were performed using the GLM procedure of the SAS software (SAS Institute, Cary, NC) at $P=0.05$. Spearman's rank order correlation coefficient $r_{\mathrm{s}}$ between yield and takeall ratings (root rot in the greenhouse and whiteheads in the field) also was determined.

For inoculum placed to the side and below seed level, regression analyses were used for both greenhouse and field experiments to develop a multiple regression model, which can be referred to as a takeall risk model. The response variable, yield

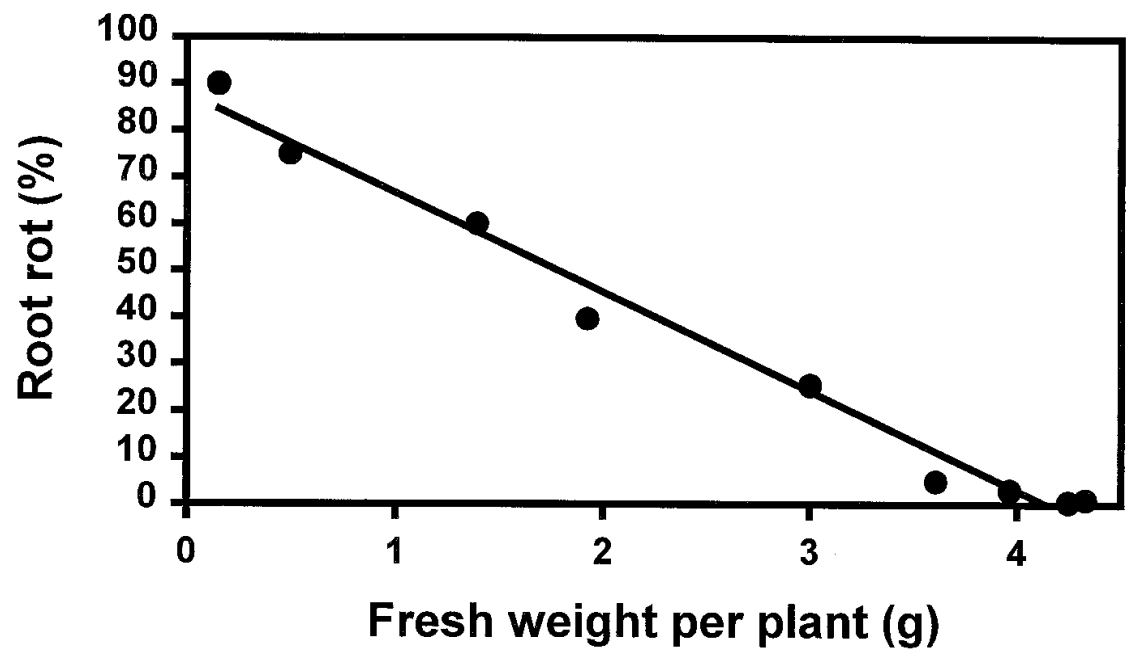

Fig. 1. Relationship between visual ratings of percentage of root rot in the greenhouse caused by take-all and fresh weight of wheat seedlings above the soil line. Spearman correlation coefficient was $r_{\mathrm{s}}=$ $-0.98, P<0.0001$, and the negative association is described by the straight line $y=-21.16 x+87.67$. 
Table 1. Effect of placement of inoculum of Gaeumannomyces graminis var. tritici in relation to the seed on wheat yields ${ }^{x}$

\begin{tabular}{lccccc}
\hline & $\begin{array}{c}\text { Greenhouse experiments, } \\
\text { fresh weight yield (g/plant) }\end{array}$ & & \multicolumn{2}{c}{$\begin{array}{c}\text { Field experiments, } \\
\text { grain yield (kg/ha) }\end{array}$} \\
\cline { 2 - 3 } \cline { 5 - 6 } Inoculum location & Exp. 1 & Exp. $\mathbf{2}$ & & Exp. 1 & Exp. 2 \\
\hline Control & $13.0 \mathrm{a}$ & $4.2 \mathrm{ab}$ & & $4,534 \mathrm{a}$ & $7,204 \mathrm{a}$ \\
Seed level & $6.8 \mathrm{e}$ & $0.1 \mathrm{e}$ & & $1,778 \mathrm{e}$ & $1,357 \mathrm{de}$ \\
$5 \mathrm{~cm}$ below & $8.2 \mathrm{de}$ & $1.4 \mathrm{~d}$ & & $1,867 \mathrm{e}$ & $690 \mathrm{e}$ \\
$10 \mathrm{~cm}$ below & $11.6 \mathrm{abc}$ & $3.0 \mathrm{c}$ & & $2,984 \mathrm{~d}$ & $2,800 \mathrm{~cd}$ \\
$15 \mathrm{~cm}$ below & $12.3 \mathrm{a}$ & $3.6 \mathrm{bc}$ & & $3,679 \mathrm{bc}$ & $4,415 \mathrm{~b}$ \\
$5 \mathrm{~cm}$ to the side & $10.2 \mathrm{bcd}$ & $1.9 \mathrm{~d}$ & & $3,156 \mathrm{~cd}$ & $3,927 \mathrm{bc}$ \\
$10 \mathrm{~cm}$ to the side & $11.9 \mathrm{ab}$ & $4.0 \mathrm{ab}$ & & $4,266 \mathrm{ab}$ & $6,037 \mathrm{a}$ \\
$15 \mathrm{~cm}$ to the side & $13.1 \mathrm{a}$ & $4.3 \mathrm{a}$ & & $4,530 \mathrm{a}$ & $7,467 \mathrm{a}$ \\
$2.5 \mathrm{~cm}$ above & $9.7 \mathrm{~cd}$ & $0.5 \mathrm{e}$ & & $3,455 \mathrm{~cd}$ & $3,295 \mathrm{bc}$ \\
\hline
\end{tabular}

$\mathrm{x}$ Values within a column followed by a common letter do not differ significantly according to analysis of variance and least significant difference analysis $(P=0.05)$.

y Placement of oat kernel inoculum relative to the seed level.

${ }^{\mathrm{z}}$ Oat kernel inoculum was positioned at $2.5,5$, and $10 \mathrm{~cm}$ (both below and to the side of the seed) instead of 5,10 , and $15 \mathrm{~cm}$.

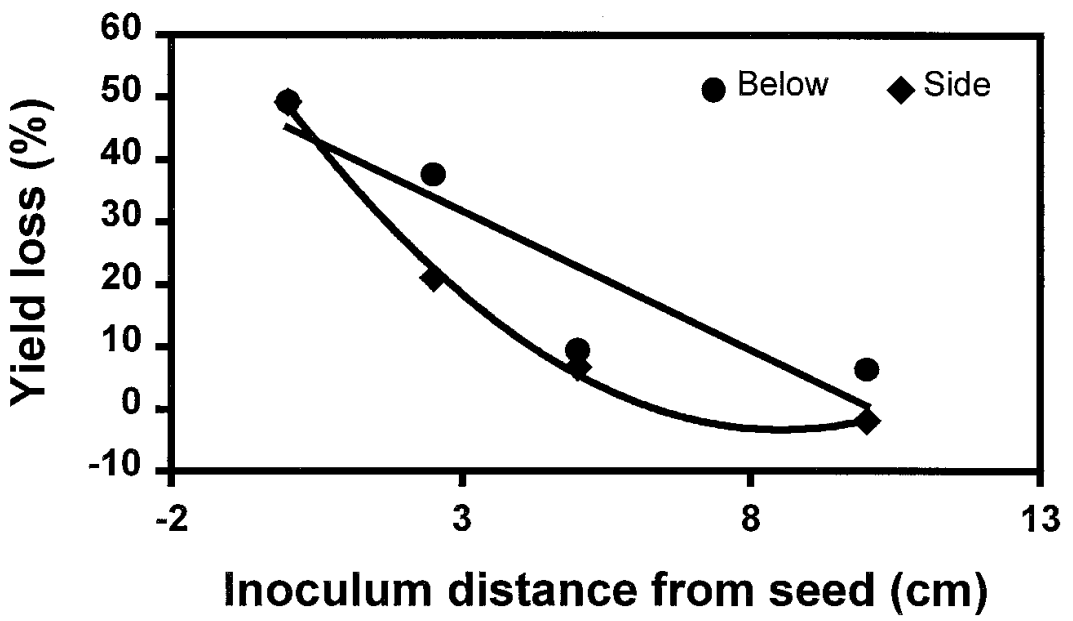

Fig. 2. Relationship between the distance from the seed of inoculum of Gaeumannomyces graminis var. tritici and amount of yield loss from take-all for inoculum placed below and to the side of seed (greenhouse experiment 1). The linear regression model has an intercept of 45.22, a slope of -4.47 , and an $R^{2}$ of $0.34(P<0.0001)$. The quadratic regression model has an intercept of 48.65 , partial slopes of -12.22 and 0.72 , and an adjusted $R^{2}$ of $0.45\left(P_{1}=0.0006\right.$ and $\left.P_{2}=0.02\right)$.

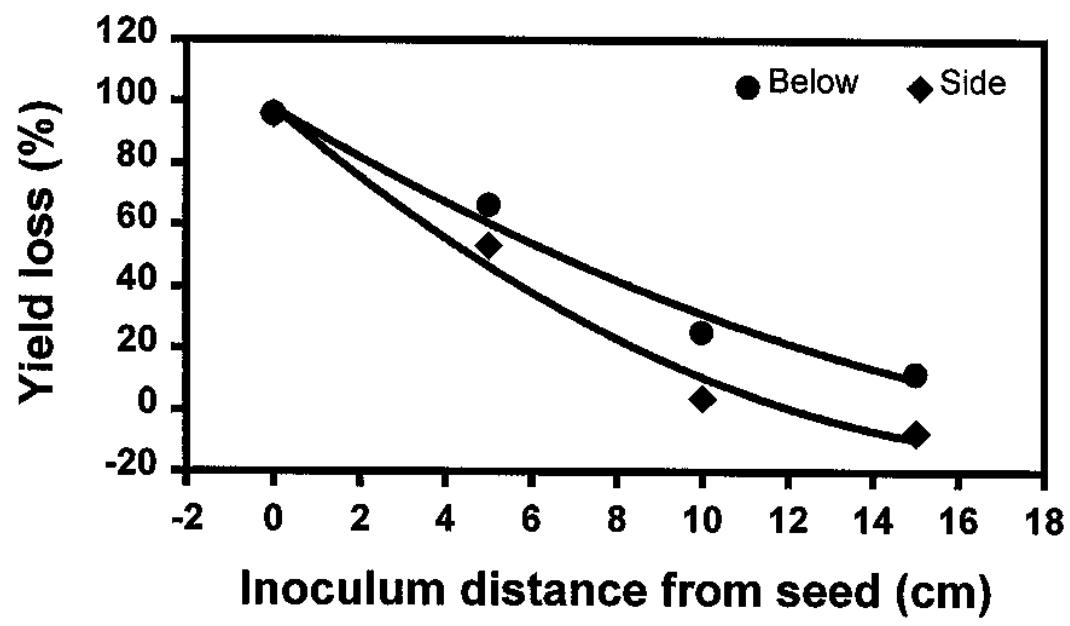

Fig. 3. Relationship between the distance from the seed of inoculum of Gaeumannomyces graminis var. tritici and amount of yield loss from take-all for inoculum placed below and to the side of seed (greenhouse experiment 2). The quadratic regression model for treatments where the inoculum was placed below the seed has an intercept of 98.12, partial slopes of -8.31 and 0.16 , and an adjusted $R^{2}$ of $0.74\left(P_{1}<0.0001\right.$ and $\left.P_{2}=0.009\right)$. The quadratic regression model for treatments where the inoculum was placed to the side of the seed has an intercept of 98.39 , partial slopes of -11.93 and 0.32 , and an adjusted $R^{2}$ of $0.73\left(P_{1}<0.0001\right.$ and $\left.P_{2}=0.001\right)$. According to the model comparison test, the two regression lines are significantly different $(P=0.0147)$. loss (YL), was regressed against the explanatory variables inoculum distance from the seed (ID), and inoculum location (IR, two options: "below" or "to the side"). Treatment 9 ( $2.5 \mathrm{~cm}$ above seed level) was not included in the regression procedure. The REG procedure of the SAS software was used. Model fit to the data was based on the method of least squares, which chooses the prediction line that minimizes the sum of the squared errors of prediction. After attempting to fit data to several models (linear, quadratic, and exponential), the quadratic grand model $\left[Y_{\mathrm{YL}}=\beta_{0}+\beta_{1} \times X_{\mathrm{ID}}\right.$ $\left.+\beta_{2} \times X^{2}{ }_{\mathrm{ID}}+\beta_{3} \times X_{\mathrm{IR}}+\beta_{4} \times X_{\mathrm{ID}} \times X_{\mathrm{IR}}\right]$ was selected for inoculum distance. The parameter $\beta_{0}$ is the $y$ intercept, the parameters $\beta_{1}, \beta_{2}, \beta_{3}$, and $\beta_{4}$ are the partial slopes, and the product $X_{\mathrm{ID}} \times X_{\mathrm{IR}}$ is the interaction term (or cross-product term) between the independent variables distance and direction. The quadratic model was chosen because of its high $R^{2}$ adj but was not always significant $(P>0.05$ for the quadratic parameter), which means that the use of a quadratic model was not always necessary. Whenever this situation was encountered, a linear model was used. The grand model was divided into two reduced models, one for inoculum below seed level and one for inoculum to the side of the seed. A model comparison test was used to determine if the two reduced models were significantly different. This test was not necessary if the two models (below and to the side) followed a different fit (linear versus quadratic).

\section{RESULTS}

Greenhouse data. Fresh weights of replicate wheat plants collected from pots in the greenhouse were highly correlated (Spearman's rank order correlation coefficient $\left.r_{\mathrm{s}}=-0.98, P<0.0001\right)$ with the percentage of the root system showing take-all lesions when observed with the dissecting microscope. The straight line $(y=-21.16 x$ $+87.67)$ for experiment 2 adequately described the negative association between the percentage of root rot and fresh weights (Fig. 1). A similar correlation was obtained in experiment 1 . Therefore, only yield data were used to quantify the effect of inoculum location on severity of take-all.

Comparison of the $2.5-\mathrm{cm}$-above seed treatment with the other treatments revealed that wheat yields were significantly $(P<0.0001$, both experiments $)$ affected by the location of take-all inoculum. Fresh weight yields were greater in greenhouse experiment 1 than experiment 2 , as indicated by yields of the noninoculated controls (Table 1). Yield reductions due to take-all were less in pots where the inoculum was positioned to the side of the wheat seed compared with corresponding treatments where the inoculum was placed below the wheat seed; however, the difference was significant only at the 10- and $15-\mathrm{cm}$ distance in experiment 2 but not in 
experiment 1 . In experiment 2 , the treatment where the oat kernels were located above the seed was not significantly different from the seed level treatment and caused severe disease, leading to $88 \%$ yield loss. In experiment 1 , the same treatment caused less disease, with only about $25 \%$ yield loss, and was statistically the same as treatments $5 \mathrm{~cm}$ below and $5 \mathrm{~cm}$ to the side of the seed. In both experiments, inoculum placed 10 and $15 \mathrm{~cm}$ to the side and $15 \mathrm{~cm}$ below were not significantly different from the noninoculated control.

In both greenhouse experiments, quadratic models significantly fit data from treatments where inoculum was placed to the side of the seed (experiment 1: $P<$ $0.0001, R^{2}$ adj $=0.45$, partial slopes $P_{1}=$ $0.0006, P_{2}=0.02$; experiment $2: P<$ $0.0001, R_{\text {adj }}^{2}=0.73$, partial slopes $P_{1}<$ $\left.0.0001, P_{2}=0.001\right)$. For inoculum placed below the seed, the prediction line showed a significant linear fit in experiment $1(P<$ $0.0001, R^{2}=0.34$ ), and a significant quadratic fit in experiment $2\left(P<0.0001, R^{2}\right.$ adj $=0.74$, partial slopes $P_{1}<0.0001, P_{2}=$ 0.009).

The model comparison tests (MCT) indicated that the regression lines representing treatments where inoculum was placed to the side and those representing treatments where inoculum was placed below seed were significantly different (Figs. 2 and 3). For experiment 1, this test was not needed because the two regression lines followed a different fit (linear versus quadratic); however, it was needed in experiment 2 where the two regression lines had the same fit and were statistically different $(P=0.01)$.

Field data. In the field experiments, both percentage of whiteheads and grain yield were measured to assess disease severity. The percentage of whiteheads observed in the field was highly correlated (Spearman's rank order correlation coefficient $\left.r_{\mathrm{s}}=-0.98, P<0.0001\right)$ with the grain yield produced by wheat plants. The negative association between whiteheads and grain yield was satisfactorily described by a straight line $(y=-0.08 x+108.74$, Fig. 4). Therefore, only grain yield data were used to quantify the effect of inoculum location on severity of take-all.

Comparison of the 2.5-cm-above seed treatment with the other treatments revealed that grain yield was affected by the location of oat kernel inoculum (experiment 1: $P<0.0001$, LSD $=611$; experiment 2: $P<0.0001$, LSD $=1560)$. As in the greenhouse, grain yields of noninoculated controls showed differences in yield potential between the two experiments (Table 1), with yields being higher in the second experiment. Both experiments showed that treatments where inoculum was placed below the seed caused higher yield reduction from take-all compared with treatments where inoculum was placed to the side of the seed. Take-all caused by the treatment where the inoculum was positioned above the wheat seed was not as severe in the field as in experiment 2 in the greenhouse, causing $24 \%$ yield loss in the first field experiment and $54 \%$ in the second. That treatment was statistically similar to treatments with inoculum 10 and $15 \mathrm{~cm}$ below and $5 \mathrm{~cm}$ to the side of the wheat seed. Treatments with inoculum placed 10 and $15 \mathrm{~cm}$ to the side of the wheat seed were not significantly different from the noninoculated control.

In both experiments, linear models significantly fit data from treatments where inoculum was placed below the seed (experiment $1: P<0.0001, R^{2}=0.64$; experiment 2: $P=0.005, R^{2}=0.36$; Figs. 5 and $6)$. Where inoculum was placed to the side of the seed, a quadratic model fit the data in experiment $1\left(P<0.0001, R_{\text {adj }}^{2}=0.77\right.$, partial slopes $P_{1}<0.0001, P_{2}=0.002$; Fig. $5)$ and a linear model in experiment $2(P<$

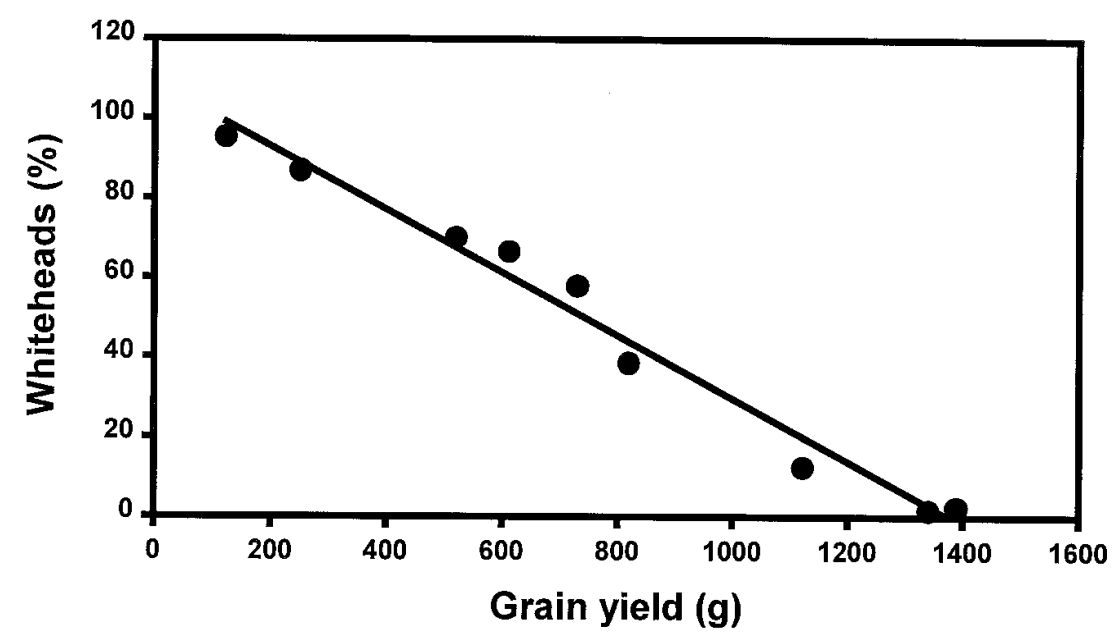

Fig. 4. Relationship between visual ratings of percentage whiteheads in the field caused by take-all and grain yield. Spearman correlation coefficient was $r_{\mathrm{s}}=-0.98$, and the negative association is described by the straight line $y=-0.08 x+108.74$.

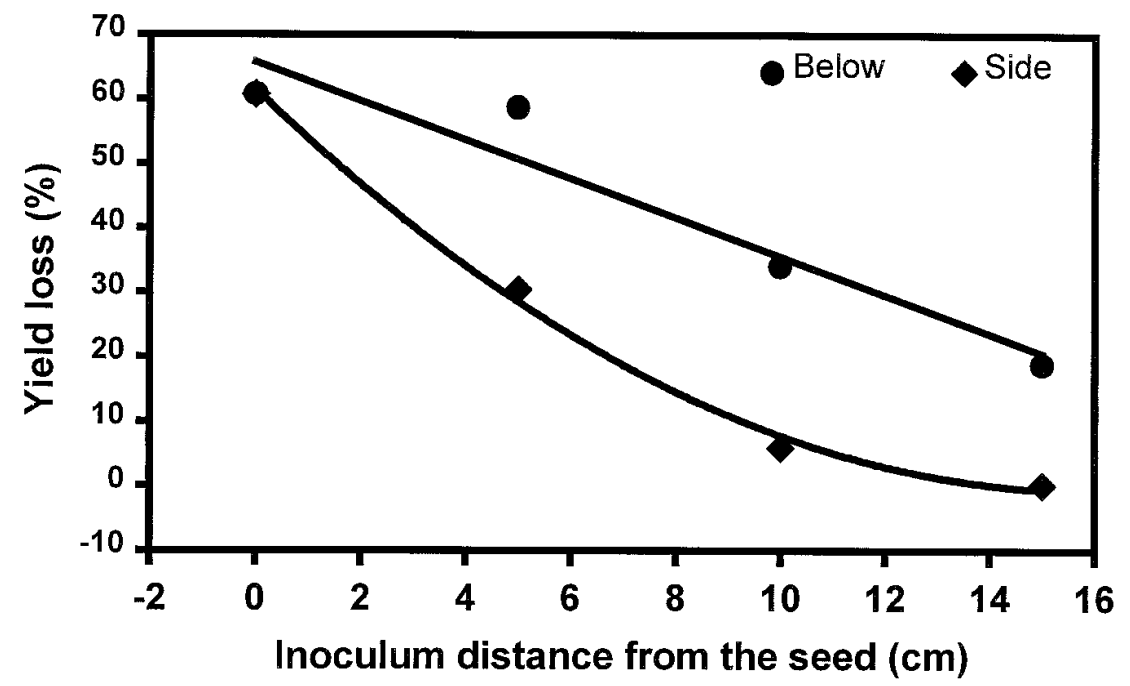

Fig. 5. Relationship between the distance from the seed of inoculum of Gaeumannomyces graminis var. tritici and amount of yield loss from take-all for inoculum placed below and to the side of seed (field experiment 1). The linear regression model has an intercept of 65.72, a slope of -3.01 , and an $R^{2}$ of $0.64(P<0.0001)$. The quadratic regression model has an intercept of 61.44 , partial slopes of -7.82 and 0.25 , and an adjusted $R^{2}$ of $0.77\left(P_{1}=0.0006\right.$ and $\left.P_{2}=0.02\right)$.
$0.0001, R^{2}=0.75$; Fig. 6). Regression lines data from inoculum placement below those where inoculum was placed to the side. Regression lines representing side treatments were always under those representing below treatments (Figs. 5 and 6). the second experiment, a model com$0.0001)$ difference between the two regression lines. Models generated from greenhouse and field data were used to predict distances that inoculum needed to be from tion in take-all compared with inoculum at seed level (Table 2).

\section{DISCUSSION}

tion and distance from wheat seed greatly influenced take-all severity in a predictable manner. In all greenhouse and field experi- 
ments, take-all was more severe when inoculum propagules were placed below the seed than at the same distance but to the side of the seed. The difference between the two locations was less in the greenhouse, but still significant as indicated by model comparison tests. We believe this difference can be attributed to the fact that soil moisture was higher in the greenhouse experiments than in the field experiments. In the greenhouse, pots were watered daily, whereas plots in the field went through several drying and wetting cycles. Smiley et al. (17) described how the amount of soil moisture affects take-all and stated that it is most severe under the wettest conditions. Because G. graminis var. tritici-colonized oat kernels were introduced $5 \mathrm{~cm}$ deep in treatments where the inoculum was placed to the side of the wheat seed, this exposed them to dry-moist cycles that occurred in the upper layer of the soil in field experiments. On the other hand, inoculum placed below the seed in the field would be in a more stable environment with regards to soil moisture. Differences in root distribution patterns between below and to the side of seed also could be a factor.
The severity of infection of wheat roots by $G$. graminis var. tritici was influenced by oat kernel inoculum distance from the wheat seed. Within the same location (below or to the side), take-all severity decreased as the inoculum was positioned further away from the seed, often to insignificant levels of disease at 10 to $15 \mathrm{~cm}$. The closer the inoculum to the seed, the earlier the pathogen will contact roots to begin infection and the shorter it will have to move to the basal stem area of the plant. This timing is important because plant age when the pathogen reaches the crown area is a large determinant in how the pathogen affects plant yield (12). The earlier the pathogen reaches the crown, the greater the yield loss.

The take-all fungus has been detected as deep as $50 \mathrm{~cm}$ below the surface. However, it has been reported that most infections occur within the upper $15 \mathrm{~cm}$. According to the models generated from field data reported here, predicted inoculum distances from the seed to achieve a $50 \%$ reduction in yield loss from take-all, compared with inoculum at seed level, are, on average, $13.2 \mathrm{~cm}$ below the seed, or $5.2 \mathrm{~cm}$

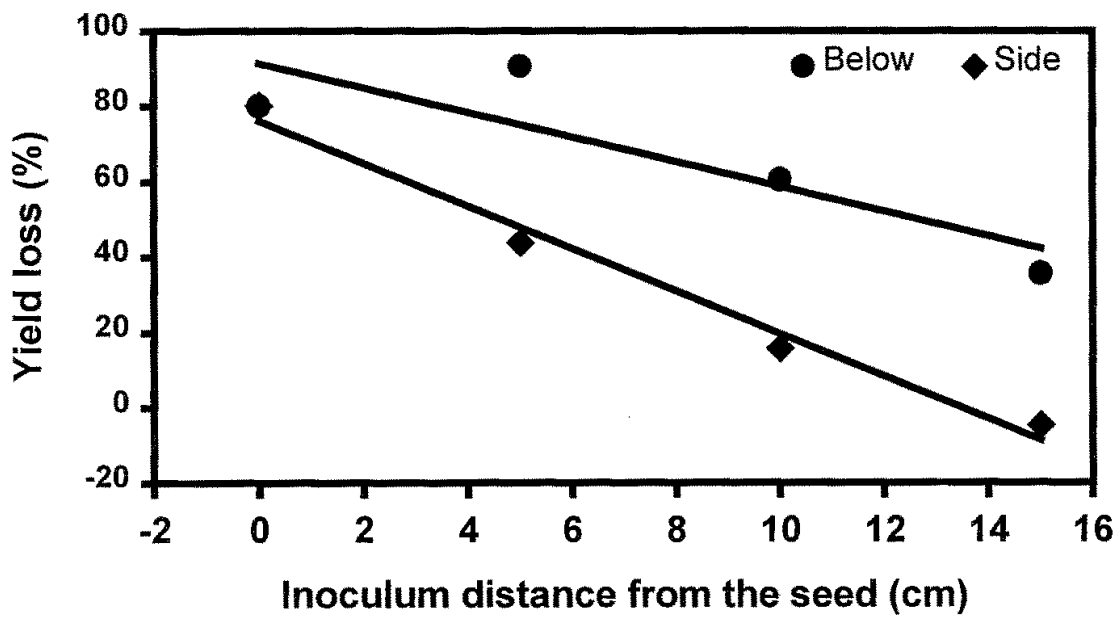

Fig. 6. Relationship between the distance from the seed of inoculum of Gaeumannomyces graminis var. tritici and amount of yield loss from take-all for inoculum placed below and to the side of seed (field experiment 2). The linear regression model for treatments where the inoculum was placed below the seed has an intercept of 91.36, a slope of -3.27 , and an $R^{2}$ of $0.36(P=0.005)$. The linear regression model for treatments where the inoculum was placed to the side of the seed has an intercept of 76.18, a slope of -5.65 , and an $R^{2}$ of $0.75(P<0.0001)$. According to the model comparison test, the two regression lines are significantly different $(P<0.0001)$. to the side of the seed. The predicted distance from the seed to achieve $90 \%$ reduction in yield loss is $11.4 \mathrm{~cm}$ when the inoculum is located to the side of the seed. The $90 \%$ reduction in yield loss for inoculum below the seed cannot be calculated because the predicted distances are significantly beyond the range used in our experiments (Table 2).

Moore and Cook (15) reported that seeding wheat directly into soil naturally infested with G. graminis var. tritici resulted in more take-all than seeding where the soil was disturbed by moldboard or disk plowing. They concluded that the size of inoculum was important to take-all epidemiology. The large infested crown segments were much more important than small root pieces. Similarly, most of the infectious inoculum resides in the upper portion of the soil profile (10). Wilkinson et al. (18) also demonstrated the importance of inoculum size and showed that cultivation practices or environmental conditions that lead to a breakdown of the debris should accelerate the reduction of inoculum in soil. Any type of tillage helps break down infested particles to smaller fragments, exposing them to more rapid decay. Therefore, the most important inoculum consists of the rows of intact, infested crown tissue. According to our results, a significant reduction in yield loss might be achieved by plowing the important inoculum pieces (crowns) to depths greater than $15 \mathrm{~cm}$, reducing the amount of inoculum in the upper (seed) layer. Theoretically, the deeper inoculum is buried below seed level, the greater the reduction in take-all damage. Our results indicate that this hypothesis needs further investigation.

Moldboard plowing often is not practiced because of soil erosion concerns. In Kansas, there are increasing hectares planted under no-till (direct-drilled) conditions. Another extrapolation of our results implies that, under no-till conditions, sowing the new crop 11 to $12 \mathrm{~cm}$ away from the row of infested crowns from the previous crop in the horizontal direction might lead to a $90 \%$ reduction of yield loss from take-all (Table 2). Even placing seed only 4.5 to $6.0 \mathrm{~cm}$ to the side of infested crowns

Table 2. Predicted inoculum distances (cm) from the seed to achieve 50, 75, and $90 \%$ reduction in yield loss from take-all compared with inoculum at seed level ${ }^{x}$

\begin{tabular}{|c|c|c|c|c|c|c|c|c|}
\hline \multirow[b]{3}{*}{ Reduction (\%) } & \multicolumn{4}{|c|}{ Distance from seed (greenhouse) } & \multicolumn{4}{|c|}{ Distance from seed (field) } \\
\hline & \multicolumn{2}{|c|}{ Experiment $1^{y}$} & \multicolumn{2}{|c|}{ Experiment 2} & \multicolumn{2}{|c|}{ Experiment $1^{y}$} & \multicolumn{2}{|c|}{ Experiment 2} \\
\hline & Below & Side & Below & Side & Below & Side & Below & Side \\
\hline 50 & 4.2 & 2.0 & 7.0 & 4.2 & 11.5 & 4.5 & 15.0 & 6.0 \\
\hline 75 & 7.2 & 3.4 & 10.5 & 7.2 & $>15^{z}$ & 8.0 & $>15^{z}$ & 10.0 \\
\hline 90 & 9.2 & 5.0 & 16.0 & 10.2 & $>15^{\mathrm{z}}$ & 11.0 & $>15^{z}$ & 11.8 \\
\hline
\end{tabular}

${ }^{\mathrm{x}}$ Predictions based upon linear and quadratic models from two greenhouse and two field experiments. Predicted distances are for inoculum directly below or to the side of seed level.

${ }^{\mathrm{y}}$ In greenhouse experiment 1 , oat kernel inoculum was positioned at $2.5,5$, and $10 \mathrm{~cm}$ (both below and to the side of the seed) instead of 5,10 , and 15 $\mathrm{cm}$.

${ }^{\mathrm{z}}$ Predicted distances are significantly beyond the range used in experiments. 
may result in $50 \%$ reduction in yield loss. Row spacing for winter wheat in Kansas varies from 15 to $30 \mathrm{~cm}$. This hypothesis, suggested from our findings, also needs to be tested.

\section{LITERATURE CITED}

1. Bailey, D. J., and Gilligan, C. A. 1999. Dynamics of primary and secondary infection in take-all epidemics. Phytopathology 89:84-91.

2. Bockus, W. W. 1983. Effects of fall infection by Gaeumannomyces graminis var. tritici and triadimenol seed treatment on severity of take-all in winter wheat. Phytopathology 73:540-543.

3. Bockus, W. W., Davis, M. A., and Norman, B. L. 1994. Effect of soil shading by surface residues during summer fallow on take-all of winter wheat. Plant Dis. 78:50-54.

4. Butler, F. C. 1953. Saprophytic behavior of some cereal root-rot fungi. I. Saprophytic colonization of wheat straw. Ann. Appl. Biol. 40:284-297.

5. Colbach, N., and Huet, P. 1995. Modeling the frequency and severity of root and foot diseases in winter wheat monocultures. Eur. J. Agron. 4:217-227.
6. Colbach, N., Lucas, P., and Meynard, J.-M. 1997. Influence of crop management on takeall development and disease cycles on winter wheat. Phytopathology 87:26-32.

7. Cook, R. J. 1981. The influence of rotation crops on take-all decline phenomenon. Phytopathology 71:189-192.

8. Cook, R. J. 1994. Problems and progress in the biological control of wheat take-all. Plant Pathol. 43:429-437.

9. Cotterill, P. J., and Sivasithamparam, K. 1988. The effect of tillage practices on distribution, size, infectivity and propagule number of the take-all fungus, Gaeumannomyces graminis var. tritici. Soil Till. Res. 11:183-195.

10. Cotterill, P. J., and Sivasithamparam, K. 1989. Inoculum of the take-all fungus (Gaeumannomyces graminis var. tritici) in a Mediterranean-type climate: spatial distribution at a field site in Western Australia. Phytophylactica 21:45-48.

11. Garrett, S. D. 1940. Soil conditions and the take-all disease of wheat V. Further experiments on the survival of Ophiobolus graminis in infected wheat stubble buried in the soil. Ann. Appl. Biol. 27:199-204.

12. Garrett, S. D. 1948. Soil conditions and the take-all disease of wheat. IX. Interaction be- tween host plant nutrition, disease escape, and disease resistance. Ann. Appl. Biol. 35:14-17.

13. Hornby, D. 1975. Inoculum of the take-all fungus: Nature, measurement, distribution, and survival. Eur. Mediterr. Plant Prot. Organ. Bull. 5:319-333.

14. Hornby, D., Bateman, G. L., Gutteridge, R. J., Lucas, P., Osbourn, A. E., Ward, E., and Yarham, D. J. 1998. Take-all disease of cereals. A regional perspective. CAB International, Wallingford, Oxon, England.

15. Moore, K. J., and Cook, R. J. 1984. Increased take-all of wheat with direct drilling in the Pacific Northwest. Phytopathology 74:10441049 .

16. Scott, P. R. 1969. Control of Ophiobolus graminis between consecutive crops of winter wheat. Ann. Appl. Biol. 63:47-53.

17. Smiley, R. W., Collins, H. P., and Rasmussen, P. E. 1996. Diseases of wheat in long-term agronomic experiments at Pendleton, Oregon. Plant Dis. 80: 813-820.

18. Wilkinson, H. T., Cook, R. J., and Alldredge, J. R. 1985. Relation of inoculum size and concentration to infection of wheat roots by Gaeumannomyces graminis var. tritici. Phytopathology 75:98-103. 